\title{
ARE GREEN MEN FROM VENUS?
}

CARL OBERMILLER

(corresponding author)

Albers School of Business and Economics

Seattle University

Seattle, Washington, U.S.A.

carlo@seattleu.edu

MATHEW S. ISAAC

Albers School of Business and Economics

Seattle University

Seattle, Washington, U.S.A.

isaacm@seattleu.edu

Abstract. A consistent finding in sustainability research is that women are eco-friendlier than men, a gap usually ascribed to differences in socialization. Our research explored a corollary process-the cognitive association of environmentalism with femininity along with the consequent negative responses of men that arise from their efforts to safeguard their masculine identity. Two studies replicated the recent discovery (Brough et al., 2016) of a mental association between environmentalism and femininity (for both men and women) and the consequent reduction in the effectiveness of conventional environmental appeals to men. This research also investigated two approaches for overcoming the effects of the implicit association of sustainability with femininity. The first considered that well-learned reflective knowledge structures about advertising or about sustainability might mitigate the resistance of men to environmental appeals. We tested whether established measures of advertising skepticism (Study 1) or sustainability literacy (Studies 1 and 2) would moderate these consequences of the green-feminine association. Whereas skepticism moderated these effects, sustainability literacy did not. The second approach for offsetting the association between sustainability and femininity was to create an environmental appeal with distinctly masculine brand-positioning elements. Two versions of an environmental appeal with different brand elements were produced-one masculine and the other feminine (Study 2 ). While men and women were equally responsive to the masculine brand positioning, the 
most positive responses were from women toward the feminine positioning. Collectively, these results corroborate the green-feminine association and demonstrate the moderating role of advertising skepticism. Furthermore, although higher sustainability literacy resulted in more pro-environmental behavior in general, it did not moderate downstream effects of the implicit green-feminine association.

Keywords: sustainability; environmental advertising; sustainability literacy; gender differences

\section{INTRODUCTION}

"Not only do men and women communicate differently but they think, feel, perceive, react, respond, love, need, and appreciate differently"-John Gray articulated these differences between the sexes in his popular book Men are from Mars, women are from Venus (1992), a work that contributed to a vast effort to identify and explain gender differences that continues until today.

One such difference that has been observed in past research is that men are less eco-friendly than women (e.g., Lee \& Holden, 1999), an effect that has been attributed to differences in socialization-women learn to be more nurturing in general (e.g., Zelezny, Chua, \& Aldrich, 2000) compared to men. Recent research (Brough, Wilkie, Ma, Isaac, \& Gal, 2016) suggests a contributing, perhaps corollary factor in that ecofriendliness is regarded as more feminine and thus a threat to males' self-perceived masculinity. In other words, although "real" Martians may be green ${ }^{1}$, Earth men, even if they are from Mars, don't want to be so.

If men are socialized in ways that make them unlikely to adopt sustainable behaviors, what are we to do, especially given that considerable marketing effort from both brand marketing and proenvironmental organizations is directed toward increasing sustainable behaviors? In this article, we report a replication and extension of the results of Brough et al. (2016). Our objectives were to 1) replicate the important observation of a cognitive association between the concepts of environmentalism and femininity, 2) replicate the demonstration that

"The origin of the characterization of Martians as "little green men" is ambiguous. Edgar Rice Burroughs described Martians as green in his 1912 novel A princess of Mars, but he includes Martian women and the men were 12 feet tall. Earlier uses of the phrase as a characterization of aliens date back to the early 1900s (cf. https://en.wikipedia.org/ wiki/Little_green_men). 
a masculine brand positioning can overcome the negative effects of this association on behavioral intentions, and 3) investigate the possibility that well-learned knowledge about advertising or about sustainability might also moderate the resistance of men to environmental appeals. We conclude with a brief discussion of implications for the marketing of sustainability.

\section{BACKGROUND}

There is extensive evidence documenting the gender gap in environmental sustainability (see, for example, Dietz, Kalof, \& Stern, 2002). Women learn to be more prosocial, altruistic, empathetic (Dietz et al., 2002), more caring (Zelezny et al., 2000), and more concerned with health and safety (Davidson \& Freudenburg, 1996). These differences are related to the propensity of women to bear the responsibility of primary child care in most societies. Family norms and social institutions thereby socialize women (relative to men) toward sustainability values.

Brough et al. (2016) contribute to this research stream the notion that men may resist pro-environmentalism because of a cognitive association between the concepts of greenness and femininity. They discovered that this association is implicit-that is, automatic and uncontrollable-but can affect explicit judgments, intentions, and behaviors. Indeed, their Study 1 showed, utilizing an established categorization task called the Implicit Association Test (IAT) (Greenwald, McGhee, \& Schwartz, 1998), that both men and women take less time to make judgments about women's names when these are paired with images of environmentallyfriendly (vs. environmentally-unfriendly) products (no such implicit association was found for men's names or photos). A shorter response latency on the IAT indicates that the paired concepts (i.e., femininity and eco-friendliness) match participants' subjective mental representation, the logic being that two concepts are cognitively linked when they are stored nearer to one another and are thus more easily retrieved from long-term memory.

Brough et al.'s (2016) Study 2, moreover, showed that both men and women label an individual bringing a reusable canvas bag to the grocery store as more feminine than someone who uses a plastic bag, regardless of whether the shopper is male or female. The implicit association between environmentalism and femininity can thus affect individuals' explicit judgments. In fact, the researchers also found in subsequent experiments that while women generally embrace the green-feminine association, 
men may be discouraged to adopt sustainable behaviors because they wish to maintain their sense of masculinity.

Research into implicit associations has been extensive since the earliest publication of Greenwald et al.'s work (1998; see Banaji \& Greenwald [2013] for a review). They are well-learned relationships between categories-Western culture, for example, is rich with positive connections to flowers and negative connections to insects, with most of us associating flowers with pleasantness and insects with unpleasantness. As a result, we more readily and automatically process connections to flowers with positive feelings and those toward insects with negative feelings, thereby making us more likely to act positively toward flowerrelevant stimuli and negatively toward insect-relevant stimuli. The research on implicit associations has been, over the past decade or so, part of the trend in psychology to characterize information processing in terms of two types: automatic and thoughtful. Perspectives such as those, for example, in Thinking, fast and slow (Daniel Kahneman, 2011), Blink (Malcolm Gladwell, 2007), and Blindspot: Hidden biases of good people (Banaji \& Greenwald, 2013) characterize human decision making as having a spectrum ranging from automatic to reflective processing. Automatic processing is primary and, in many cases, directive of later thought, suggesting that implicit associations may guide even the most thoughtful of decisions.

Much of the work in implicit associations has focused on racial biases, with the finding that an implicit preference for whites is found in about $75 \%$ of the U.S. population (Banaji \& Greenwald, 2013). Across dozens of studies, that association has been shown to be related to moderate forms of racial prejudice-attitudes, friendliness, recommendations for medical treatments, evaluations of job applicants-but not necessarily to overt (public) expressions or behaviors. The implication is that these cognitive associations may result in automatic (less conscious) responses but do not necessarily dictate reflective (more thoughtful) ones.

The implicit association for the gender gap in sustainability is as follows: men and women are socialized to associate sustainability with femininity. This association may be direct because women are more likely to be caretakers of the environment or indirect because both sustainability and women are associated with such characteristics as being nurturing, caring, cooperative, altruistic, and ethical. A link to femininity is also bolstering and positive for most women but threatening and negative for most men. The prospect of green behavior therefore triggers an automatic, implicit association with femininity, which is positive for women but negative for men. 
As Banaji and Greenwald stress in Blindspot (2013), few people are free of implicit associations, even though most of us do not act upon them. For example, the vast majority of people hold implicit pro-white associations but few of them are overtly prejudiced. In similar fashion, not all women act in environmentally friendly ways and not all men act upon anti-green instincts. Why do we not always act in accordance with our implicit associations? And what might be done to increase pro-social actions that might be discouraged by implicit associations?

The answer to the first question is fairly straightforward-automatic processing may be offset by reflective processing. When we think carefully about a decision, our implicit associations can be overwhelmed by a more complete assessment and weighing of available knowledge and implications. The challenge, as always, is that people resist careful, thoughtful analysis. What can we do then to offset the negative (usually for men) effects of the implicit association of greenness and femininity?

Banaji and Greenwald (2013) are not sanguine about an easy solution to the problem. Stereotypes, as they describe, are a prominent form of implicit association and a difficult response to modify. They are easily, almost unavoidably formed, and efforts to counter them through specific learning (e.g., "Blacks are good"; "Females are strong," etc.) have been shown to produce, at best, only short-term eliminations of the implicit attitude effect. Nevertheless, Gladwell (2007) comments on our ability to control the effects of implicit associations: "The answer is that we are not helpless in the face of our first impressions. They may bubble up from the unconscious-from behind a locked door inside of our brain-but just because something is outside of awareness doesn't mean it's outside of control" (p. 96). He goes on, however, to describe the necessary changes as substantial. To overcome racial bias, for example, "requires that you change your life so that you are exposed to minorities on a regular basis and become comfortable with them and familiar with the best of their culture..." (p. 97). Therefore, to overcome the negative effects of implicit associations that have developed over a lifetime, we may need an equivalent lifetime of counter-association learning. Such a lengthy time frame, unfortunately, is not reasonable for designing a marketing intervention. ${ }^{2}$ Perhaps future generations will grow up in a world that associates pro-environmentalism with manliness (as well as femininity); until then, we are left to deal with associations as they currently exist.

${ }^{2}$ On the plus side, evidence shows that IAT-indicated stereotypes vary across cultures. We should no doubt expect to see differences, therefore, in the green-feminine association across countries. 
If unlearning implicit associations is problematic, perhaps another option is to attempt to bring them to light. Banaji and Greenwald use the analogy of cameras on cars that alert drivers to other cars in their blindspots. We need devices that will alert us to the effects of our automatic processing - something that essentially shouts out, "Hey, don't trust your first instinct here; it's wrong!" At that point, the prediction is that thoughtful, reflective processing will overwhelm the automatic response. The challenge once again, however, is how to encourage people to think carefully about something that does not warrant careful thought. Although there are many instances of communication that appear to have been successful in generating thoughtful decisionmaking, consumers are especially vigilant against marketing efforts that attempt to get them to think more than they want (Friestad \& Wright, 1994).

Still another option would be to use persuasion tools to offset the effect of automatic processing with countervailing automatic processing at the point of choice. Brough et al. (2016) demonstrated that framing green behavior or products as masculine could reduce the negative predisposition of men toward donating to a green non-profit. They found that repositioning the advocating organization as more masculine increased men's likelihood to donate as compared to men who were presented with conventional green positioning (i.e., feminine), and even matched the donation likelihood of women. Thus, the subtle effect of rebranding green behavior as masculine offset the well-learned association of green behavior with femininity.

We pose a related question: can a well-learned association offset implicit associations in the context of behaviors? When it comes to race, for example, most people usually do the right thing despite implicit learning, that is, even though the majority exhibit implicit race bias, most of them almost never act on racial stereotypes. Is this because such individuals have well-integrated racial equality learning that is easily called upon to counter negative initial tendencies whenever racial stereotyping is an option? If so, can we identify well-learned cognitive structures that will moderate the effects of implicit associations when it comes to green behavior? Perhaps two such structures (knowledge areas) are advertising skepticism and sustainability literacy. 


\section{RESEARCH QUESTIONS}

As noted above, this research had three objectives. The first two were to replicate the innovative findings of Brough et al. (2016): do men exhibit a cognitive association between environmentalism and femininity that limits their acceptance of pro-sustainability messages and, if so, can this association be overcome by positioning the brand of the advocating party as masculine? The third objective was to investigate whether the downstream effects of the green-feminine association on explicit judgments and men's behavioral intentions would be moderated by either one of two cognitive structures-advertising skepticism and sustainability literacy.

Obermiller and Spangenberg (1998) defined skepticism toward advertising (ad skepticism) as a marketplace belief (a fundamental belief about how the marketplace works); it is a well-learned tendency to disbelieve the informational claims of advertising, a well-learned cognitive association based on socialization and countless consumer experiences. They developed and validated a scale to measure the construct (SKEP) and demonstrated empirical support for a hypothesized nomological network, linking ad skepticism to attitudes toward advertising, marketplace experiences (most important in this context), and consumer socialization. Given, therefore, that the green-feminine association may be socialized by media and advertising, we hypothesized that advertising skeptics would be more likely to dismiss the implicit association between environmentalism and femininity when making explicit judgments.

Second, we investigated moderation by sustainability literacy, which is conceptualized as an integrated system of knowledge and attitudes, along with behaviors or intentions, that guide decisions with respect to sustainability. Obermiller and Atwood (2014), for instance, developed SustLit, a scale of sustainability literacy, and demonstrated its reliability and nomological validity in a series of studies. We reasoned that people who have well-integrated knowledge about sustainability and environmentalism may be able to recruit this knowledge to counter the initial, implicit green-feminine association. Thus, we hypothesized that high sustainability literacy would counteract the implicit association between femininity and eco-friendliness, thereby reducing the negative effects of a green-feminine association on explicit judgments and behavioral intentions. 


\section{STUDY 1}

Study 1 was designed to assess whether the green-feminine association manifested itself in participants' explicit judgments and to investigate whether ad skepticism or sustainability literacy moderated this effect. Two hundred adults (mean age $=35.90$ years, $S D=11.68$; $50.0 \%$ female) recruited through an online panel (Amazon Mechanical Turk) participated in an experiment that manipulated the gender and behavior of a consumer in a shopping scenario. The experiment, largely a replication of Study 2 of Brough et al. (2016), had a 2 (green or non-green behavior) x 2 (male or female shopper) between-participant design. The information provided about shopper behavior was whether the shopper was using a reusable bag (green) or a plastic one (non-green). The shopper was described as either a man or a woman. The scenario instructions were as follows: "Imagine you are at your local grocery store and see a [man/woman] leaving the checkout lane carrying [his/her] groceries in a [plastic bag/reusable canvas bag]," and were accompanied by images of plastic (or reusable canvas) bags containing groceries (Exhibit 1).
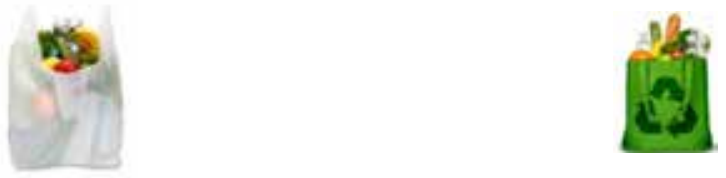

Exhibit 1: Grocery Bag Images (Study 1)

After reading the scenario, participants characterized the shopper on a set of trait scales. Out of 11 traits presented randomly for each subject, two traits were intended as manipulation checks (eco-friendly and wasteful), three as measures of masculinity (masculine, macho, and aggressive), and three as measures of femininity (feminine, gentle, and sensitive) while three were gender-neutral distractors (athletic, attractive, and curious).

Participants also completed the 9-item SKEP scale (Obermiller \& Spangenberg, 1998) and a 19-item scale of sustainability literacy ${ }^{3}$ which was a subset of the 75 -item SustLit scale (Obermiller \& Atwood, 2014). ${ }^{4}$ This reduced scale measured knowledge of climate change, energy,

${ }^{3}$ The psychometric characteristics of the SKEP and SustLit scales have been demonstrated in the cited articles. The 19-item subset from SustLit showed a correlation of $r=.87$ with the larger scale knowledge items across eight applications with over two thousand participants.

${ }^{4}$ See the Appendix for the items of the two scales. 
planetary ecosystems, systems concepts, social justice implications of sustainability, and organizational/business sustainability concepts. After reverse-coding certain items, the nine SKEP items were averaged to form an overall SKEP rating (ranging from 1 to 5 , with 5 denoting greater skepticism) and the nineteen SustLit items were averaged to form an overall SustLit rating (ranging from 1 to 5 , with 5 denoting greater sustainability literacy).

\section{Results of Study 1}

Manipulation checks were successful-for the entire sample, the reusable (vs. plastic) bags led to higher ratings of eco-friendliness (4.44 vs. $1.77 ; t(198)=19.43, p<.001)$ and lower ratings of wastefulness $(1.37$ vs. $2.54 ; t(198)=-7.70, p<.001)$ on 5 -point scales. The three measures of masculinity were averaged to form a single composite measure $(\alpha=.80)$ and likewise with the three measures of femininity $(\alpha=.75)$, producing scales of masculinity and femininity ranging from 1 to 5 . Overall, male shoppers were perceived as more masculine $(2.22$ vs. $1.57 ; t(198)=5.42$, $p<.001)$ and less feminine $(2.37$ vs. $2.86 ; t(198)=-3.64, p<.001)$ than female shoppers.

We conducted a 2 (green or non-green behavior) x 2 (male or female shopper) analysis of variance with the composite femininity measure as our dependent variable. As expected, there was a main effect of shopper gender $(F(1,196)=15.41, p<.001)$ such that female shoppers were rated as more feminine than male shoppers (2.86 vs. 2.37). More importantly, we also found a main effect of shopping behavior $(F(1,196)=33.19, p<$ .001) wherein green behavior (reusable bag) was rated as more feminine than non-green behavior (2.96 vs. 2.24), regardless of shopper gender. Green female shoppers were rated as more feminine than non-green female shoppers (3.17 vs. 2.54), and green male shoppers were also rated as more feminine than non-green male shoppers (2.76 vs. 1.97). The shopper gender $\mathrm{x}$ behavior interaction was non-significant $(F(1,196)=$ $.46, p>.49)$.

Next, we conducted a 2 (green or non-green behavior) x 2 (male or female shopper) ANOVA with the composite masculinity rating as our dependent variable. There was again a main effect of shopper gender $(F(1,196)=29.14, p<.001)$ such that female shoppers were rated as less masculine than male shoppers ( 1.57 vs. 2.22$)$. There was no significant main effect of information cue $(F(1,196)=.32, p>.57)$; that is, green versus non-green behavior did not affect ratings of masculinity (1.93 vs. 1.87). We also did not observe a significant shopper gender $\mathrm{x}$ behavior interaction $(F(1,196)=.78, p>.37)$. 
The effect of green behavior on perceptions of femininity was also independent of the gender of the study participant. An ANOVA with participant gender included as a third factor returned neither a main effect of participant gender $(F(1,191)=.16, p>.69)$ on nor a significant participant gender $\mathrm{x}$ behavior interaction $(F(1,191)=.32, p>.57)$ with perceptions of femininity. Likewise, the effect of green behavior on perceptions of masculinity was independent of the gender of the viewer-there was neither a main effect of participant gender $(F(1,191)=$ $.01, p>.92)$ on nor a significant participant gender $\mathrm{x}$ behavior interaction $(F(1,191)=1.22, p>.27)$ with perceptions of masculinity.

Shoppers with a reusable bag were thus perceived to be more feminine but not less masculine. Whether the shopper, or the person making the judgment, was male or female did not matter. As such, these results replicate those of Brough et al.'s (2016) Study 2, and we concur with their conclusions: "the green-feminine association is prevalent across both genders ... and this association may discourage men from engaging in green behaviors, particularly if they are motivated to maintain a macho image and wish to avoid being stereotyped as feminine" (Brough et al., 2016: 6).

Do SKEP or SustLit moderate the effect? SKEP was first examined as a moderator of the relation between shopper behavior and femininity ratings. Shopper behavior $(0=$ non-green, $1=$ green $)$ and SKEP were entered in the first step of the regression analysis, followed by the interaction term between shopper behavior and SKEP in the second step. This explained a significant increase in variance in femininity ratings $\left(\Delta R^{2}=.02, F(1,192)=3.84, p=.05\right)$. SKEP was therefore a significant moderator of the relationship between shopper behavior and femininity ratings.

To decompose this interaction, we examined the relationship between SKEP and femininity ratings for each shopper behavior condition (Aiken, West, \& Reno, 1991; Spiller, Fitzsimons, Lynch Jr., $\&$ McClelland, 2013). For the green behavior condition, there was a significant negative association between SKEP and femininity ratings $(\mathrm{B}=-.25, \mathrm{SE}=.11, t(97)=-2.35, p<.02)$. For the non-green behavior condition, however, there was no significant relationship between SKEP and femininity ratings $(\mathrm{B}=.05, \mathrm{SE}=.11, t(95)=.44, p>.65)$. In other words, the higher participants were in advertising skepticism, the less likely they were to judge green behavior as feminine (Figure 1). This result is consistent with our hypothesis that ad skeptics are less likely to be affected by the implicit association between environmentalism and femininity when making explicit judgments. 
- High Skep (Mean Skep + 1 SD) -- Low Skep (Mean Skep - 1 SD)

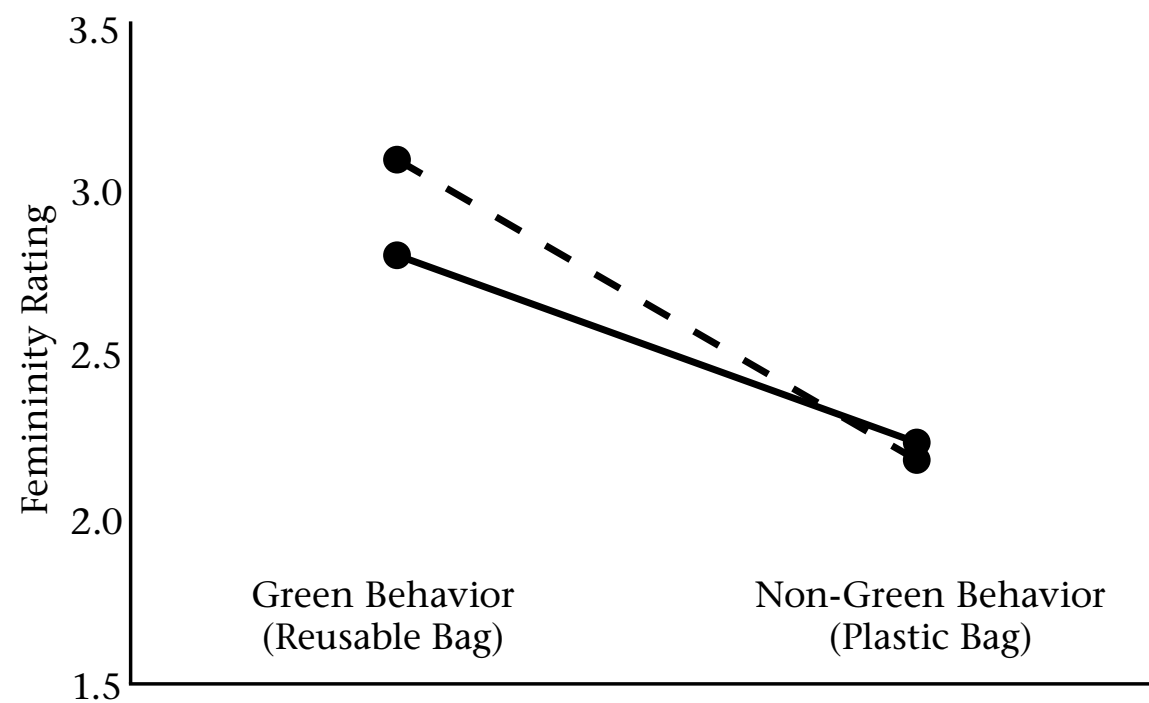

Figure 1: Association of Femininity and Green Behavior at High vs. Low Levels of Advertising Skepticism (Study 1)

To identify the range of SKEP ratings for which the simple effect of shopping behavior was significant, we used the Johnson-Neyman technique. The analysis revealed that there was a significant effect of green/non-green behavior for any SKEP rating below $4.72\left(\mathrm{~B}_{\mathrm{JN}}=-.42\right.$, $\mathrm{SE}=.21, \mathrm{p}=.05$ ) on a 5 -point scale, but not for any SKEP rating greater than 4.72 .

To examine sustainability literacy as a moderator in the behaviorfemininity relationship, we conducted another regression analysis in which shopper behavior $(0=$ non-green, $1=$ green $)$ and SustLit were entered in the first step. The interaction term between shopper behavior and SustLit was entered in the second step, and it explained a directional, but non-significant, increase in variance in femininity ratings $\left(\Delta R^{2}=.01, F(1,189)=2.03, p=.16\right)$. SustLit, therefore, was not a significant moderator of the relationship between shopper behavior and femininity ratings. However, given that the interaction was approaching the conventional threshold of marginal significance, we nonetheless examined the relationship between SustLit and femininity ratings for each shopper behavior condition (Aiken et al., 1991; Spiller et al., 2013). For the green behavior condition, the association between SustLit and femininity ratings was non-significant $(\mathrm{B}=-.15, \mathrm{SE}=.19, t(94)=-.78$, $p>.43)$. For the non-green behavior condition, however, there was a significant negative relationship between SustLit and femininity ratings 
$(\mathrm{B}=-.57, \mathrm{SE}=.22, t(95)=-2.58, p<.02)$. In other words, the higher participants were in sustainability literacy, the less likely they were to judge non-green behavior as feminine (these results are illustrated in Figure 2). Lastly, we applied the Johnson-Neyman technique once again and found a significant effect of green/non-green behavior for any SustLit rating above $2.93\left(\mathrm{~B}_{\mathrm{JN}}=-.43, \mathrm{SE}=.22, \mathrm{p}=.05\right)$ but not for any SustLit rating below 2.93 .

- High SustLit (Mean SustLit + 1 SD) - - Low SustLit (Mean SustLit - 1 SD)

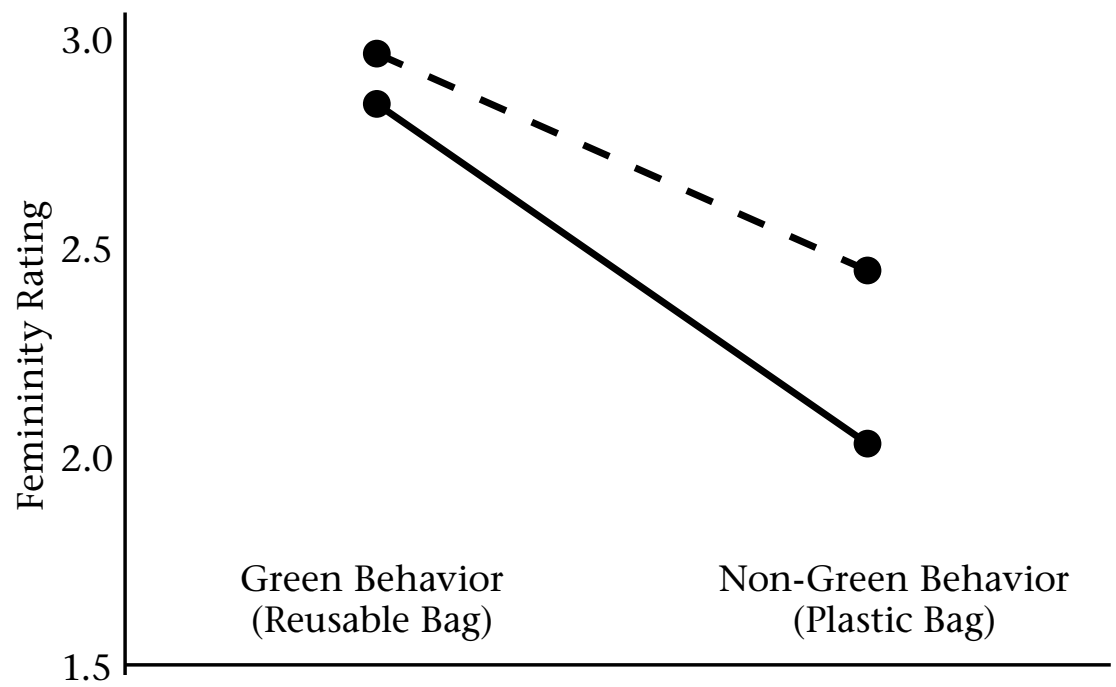

Figure 2: Association of Femininity and Green Behavior at High vs. Low Levels of Sustainability Literacy (Study 1)

Such results are inconsistent with and even directionally opposite our hypothesis that high sustainability literacy will counteract the implicit association between femininity and eco-friendliness. We found that high levels of SustLit, rather than attenuating differences in femininity ratings for green versus non-green behavior, exaggerated these differences to some degree.

\section{STUDY 2}

Study 1 showed that both men and women explicitly judge a person engaging in environmental [non-environmental] behavior to be more [less] feminine, thereby replicating Study 2 of Brough et al. (2016). We presume that people make these explicit judgments because they hold an implicit association between femininity and green behavior. We also extend the work of Brough et al. (2016) by showing that participants who 
are high in advertising skepticism are less likely to exhibit the greenfeminine association in their explicit judgments.

With respect to sustainability literacy, we found no evidence in support of our hypothesis that participants who are high in sustainability literacy will be less likely to exhibit the green-feminine association in their explicit judgments. In fact, we found directional evidence to the contrary, that participants who are high in sustainability literacy are more likely to exhibit the green-feminine association in their explicit judgments.

Why might this be? One possible explanation is that the same sustainability cues that trigger an implicit association to femininity may also trigger sustainability literacy knowledge, thereby making it more likely that those with high sustainability literacy will exhibit the green-feminine association in their explicit judgments and behavioral intentions. We probe this further in Study 2, which was designed to replicate the finding of Brough et al. (2016) that the green-feminine association affects men's behavioral intentions. Once again, we investigated moderation by other well-learned knowledge. Moreover, since our evidence with respect to sustainability literacy in Study 1 was relatively weak, we decided to focus exclusively on the moderating effect of SustLit in Study 2.

Two hundred thirty-six adults (mean age $=36.44$ years, $\mathrm{SD}=12.00$; $57.0 \%$ female) were recruited for an online study (through Amazon Mechanical Turk) which addressed two related questions. First, could we replicate the demonstration that marketing promotional tactics can overcome men's negative responses to the green-feminine association? Showing that this resistance could be overcome by positioning green appeals with cues that offset associations to femininity would be a replication of Brough et. al.'s (2016) Study 6. Second, does sustainability knowledge moderate the decision to act upon a pro-environmental request? The study was a 2 (female or male brand positioning) x 2 (gender of participant) factorial between-participants experiment.

Each participant was randomly assigned to either a feminine or masculine positioning of a donation request for an environmental nonprofit organization. The gender positioning elements are illustrated and listed in Exhibit $2 .^{5}$

${ }^{5}$ These executions were pre-tested and found to be equivalent in perceptions that the organization was pro-environmental, that they differed in masculinity and femininity, and that both referred to saving unspoiled natural environment. 


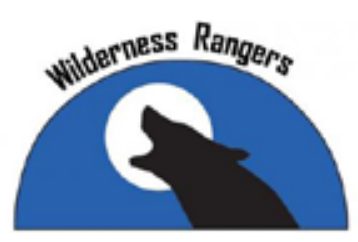

Preserving wilderness

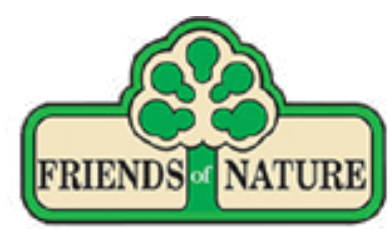

Preserving nature areas

Exhibit 2: Masculine and Feminine Brand Positions (Study 2)

Different elements:

- Title

» Masculine: Wilderness Rangers

» Feminine: Friends of Nature

- Logo

» Masculine: Black and dark blue colors with howling wolf symbol, bold/straight font

» Feminine: Green and light tan colors with tree symbol, frilly font

- Mission

» Masculine: Preserving wilderness

» Feminine: Preserving nature areas

Participants saw the description of their assigned organization along with its title, logo, and mission. They were asked about their likelihood of donating, and this served as the primary dependent variable and behavioral intention question. They were then asked about their likelihood of wearing a t-shirt featuring the organization's logo and their perceptions about how such a t-shirt would make them feel either masculine or feminine.

After seeing and responding to the initial brand positioning, participants were told that there were actually two non-profits soliciting donations and were shown both brand positions. They were then asked to complete a final dependent measure, a 10-point scale where $1=$ much more likely to donate to Friends of Nature and $10=$ much more likely to donate to Wilderness Rangers. Participants could not go back to change previous answers.

After the dependent measures, participants completed the 19-item sustainability literacy scale and gender and age questions. As in Study 1, the nineteen SustLit items were averaged to form an overall SustLit rating (ranging from 1 to 5 , with 5 denoting greater sustainability literacy). 


\section{Results of Study 2}

Our brand positioning manipulation check was successful. For the entire sample, wearing a "Friends of Nature" t-shirt was considered less masculine (3.05 vs. $3.98 ; t(232)=-4.30, p<.001)$ and more feminine $(3.79$ vs. $2.94 ; t(232)=3.92, p<.001)$ than wearing a "Wilderness Rangers" t-shirt.

To test whether men and women differed in response to the brand positions, we conducted a 2 (masculine or feminine brand positioning) x 2 (male or female participant) analysis of variance with willingness to donate as our dependent variable. While there was no main effect of brand positioning $(F(1,224)=.96, p>.32)$, there was a main effect of participant gender $(F(1,224)=5.78, p<.02)$ such that female participants were more willing to donate than male participants (4.68 vs. 4.12 ). More importantly, we also found a marginally significant interaction between brand positioning and participant gender $(F(1,224)=2.76, p<.10)$ planned contrasts showed that while women versus men did not differ in their donation response to "Wilderness Rangers" (more masculine positioning; 4.37 vs. $4.20 ; F(1,224)=.25, p>.61)$, women were more willing to donate in response to "Friends of Nature" (more feminine positioning; 4.94 vs. $4.06 ; F(1,224)=9.09, p<.01)$. These results are displayed in Figure 3.

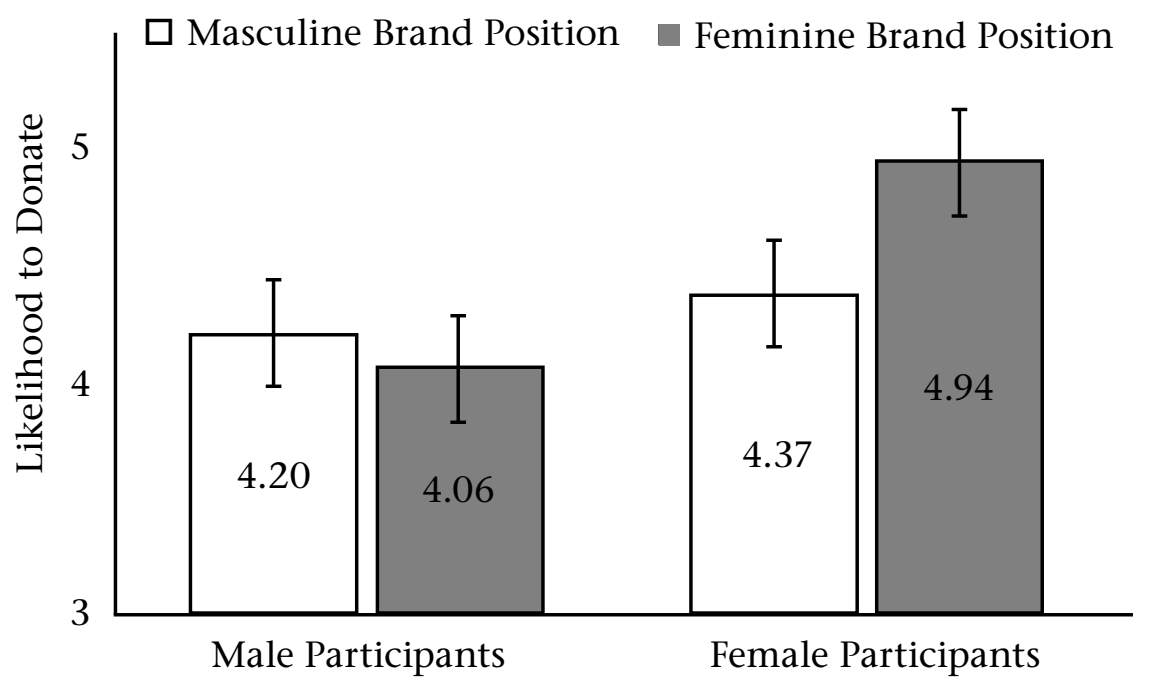

Figure 3: Effects of Brand Position and Participant Gender on Likelihood to Donate to Green Nonprofit Organization (Study 2)

Our results were somewhat weaker when we ran the same ANOVA with participants' likelihood of wearing a t-shirt featuring the 
organization's logo as the dependent variable. There was no main effect of brand positioning $(F(1,224)=.73, p>.39)$ nor a main effect of participant gender $(F(1,224)=.73, p>.39)$. The interaction between brand positioning and participant gender was also non-significant ( $F(1$, $224)=2.29, p=.13)$, although we ran planned contrasts nevertheless since it was approaching the conventional threshold of marginal significance. There we found that women versus men did not differ in their willingness to wear a "Wilderness Rangers" (more masculine positioning) t-shirt (4.72 vs. $4.89 ; F(1,224)=.20, p>.65)$. Women, though, were marginally more willing to wear a "Friends of Nature" (more feminine positioning) t-shirt $(4.89$ vs. $4.28 ; F(1,224)=3.08, p=.08)$.

The final dependent measure was the 10-point scale directly comparing donation willingness for the two brand positions, with higher numbers indicating a more positive response to the male positioning. Results of this measure were analyzed with analysis of variance. Overall, there was no effect of the initial brand presentation (5.89 for initial presentation of "Friends" vs. 5.91 for initial presentation of "Wilderness"; $F(1,211)=.08, p>.77)$ but there was a pronounced effect of gender $(5.32$ for women vs. 6.67 for men; $\mathrm{F}(1,211)=12.17, p<.001)$, indicating a strong preference of men for the "Wilderness Rangers" brand positioning. On this measure, women were almost equally responsive to the two brand positions regardless of the first one they saw, while men were more willing to donate to the more masculine positioning.

Taken together, these findings are consistent with those of Brough et al. (2016). The interaction effect of participant gender and brand positioning on willingness to donate, although only marginally significant, replicated their Study 6 results. However, whereas they found that a masculine brand positioning could raise men's responses to the level of women, our results showed that masculine positioning may sometimes lower women's responses to the level of men.

To examine sustainability literacy as a moderator of the participant gender-donation likelihood relationship, we conducted a regression analysis after first restricting our sample to those who had initially encountered the masculine brand positioning. Participant gender $(0=$ female, $1=$ male $)$ and SustLit were entered in the first step. The interaction term between participant gender and SustLit was entered in the second, and it explained a non-significant amount of variance in femininity ratings $\left(\Delta R^{2}=.00, F(1,99)=.01, p>.90\right)$. Similarly, when we focused only on those who had first encountered the feminine brand positioning, the interaction term between participant gender and SustLit entered in the second step explained a non-significant amount of variance in femininity ratings $\left(\Delta R^{2}=.01, F(1,120)=1.31, p>.25\right)$. SustLit 
was therefore not a significant moderator of the relationship between participant gender and the likelihood of donating to either organization.

Similar non-significant results were obtained when the moderating role of sustainability literacy with respect to the two other dependent variables (likelihood of wearing the organization's t-shirt and direct comparison of donation willingness for the two brand positions) was examined. Separate linear regressions revealed, however, that across all participants (independent of positioning and participant gender), greater sustainability literacy was associated with a marginally higher likelihood to donate $(\mathrm{B}=.51, \mathrm{SE}=.28, t(226)=1.86, p<.07)$ and a marginally higher likelihood of wearing either organization's $\mathrm{t}$-shirt $(\mathrm{B}=.58, \mathrm{SE}=$ $.32, t(226)=1.80, p=.07)$.

\section{CONCLUSIONS}

Consistent with earlier research, we observed that men were less willing to donate to a pro-environmental organization when it adopted a feminine brand positioning (Study 2). This reluctance may be due in part to an association of green behavior with femininity. We thus replicated the finding of Brough et. al. (2016) that both men and women associate green behavior with femininity but do not associate nongreen behavior with masculinity (Study 1). Acknowledging the existence of an implicit green-feminine association that discourages men from pro-environmental behavior is an important contribution to both our understanding of gender differences and our attempts to promote sustainability. The association of femininity with environmentalism represents an obstacle to changing men's behavior, one that marketers and policy makers should address.

Overcoming implicit associations, in general, represents a significant challenge. Three typical approaches are 1) avoiding the association by eliminating the problematic cue, 2) invoking reflective thinking to overwhelm the effect of the association, and 3) offsetting the negative association with other, more positive associations. The first of these has been used, for example, in "blind" reviews that mask gender, nationality, race, or other characteristics of applicants or students. It is not feasible, however, to eliminate the pro-environmentalism of proenvironmentalism appeals-pro-environmentalism is the central, not a peripheral, aspect of the issue.

As mentioned above, invoking reflective thinking is difficult given that people are notorious "cognitive misers" (Fiske \& Taylor, 2013) who 
do not want to be forced to think carefully or completely. An alternative, therefore, is to identify well-learned knowledge structures-such as skepticism and sustainability literacy-that may be invoked by the same stimuli that produce the implicit associations. Given that the green-feminine association may be socialized by media and advertising, advertising skepticism, for instance, should lead participants to dismiss the implicit association between environmentalism and femininity when making explicit judgments. Indeed, this is exactly what we observed in Study 1. Sustainability knowledge, if available, should facilitate reflective thinking that would override the negative effects which the environmentalism-femininity association has for men. Our results with respect to sustainability knowledge (discussed below), however, do not support this conclusion.

The final approach-offsetting the negative association with other associations-may be the process underlying the brand positioning manipulation in Study 2. Although positioning the pro-environmental appeal as more masculine did not significantly improve effectiveness with the men in our study, it significantly decreased the appeal's effectiveness with the women. While it is possible then that the women experienced a negative implicit association with masculinity, an alternative explanation is that the masculine positioning was simply inappropriate for women. Pro-sustainability marketers should thus recognize that gender is an important segmentation variable and consider a different or genderneutral brand position as an effective strategy.

As for reflective thinking functioning as a countervailing tool, our investigation yielded mixed results with respect to sustainability literacy. We were encouraged by our finding in Study 2 that greater sustainability literacy was associated with a marginally higher likelihood to donate to a pro-environmental organization (across men and women and irrespective of the masculinity/femininity of the brand positioning). Jesuit schools have always embraced the goal of increasing sustainability literacy, and should therefore be pleased to see evidence that such an effort has positive consequences. Be that as it may, our hypothesis that high sustainability literacy would counteract the implicit association between femininity and eco-friendliness, making it less likely for the green-feminine association to be observed in explicit judgments and behavioral intentions, was not supported. Sustainability literacy was not a significant moderator of previously observed green-feminine effects in either study. In fact, high levels of SustLit in Study 1 somewhat exaggerated rather than attenuated the differences in femininity ratings for green versus non-green behavior. Nevertheless, continuing to teach sustainability on campuses should have positive effects in general, given 
that high sustainability literacy in Study 2 was associated with a greater propensity to donate to a pro-environmental organization. From our investigation, however, there is no evidence to support the claim that sustainability literacy will eliminate or attenuate, at least in the short run, previously established consequences of the green-feminine association.

Is there hope for men? In a recent presentation on the "The Selling of Implicit Associations," Greenwald (2017) summarized the history of implicit association research and ended with a description of recent applications of the idea, including frequent references in trials, hiring, and job evaluations where race, gender, and other biases may often influence judgments. He specifically recognized a burgeoning industry in the training of techniques designed to eliminate implicit biases, although his conclusion was far from optimistic: despite two decades of research on implicit associations and earnest efforts to discover techniques for minimizing the negative inclinations they may produce, no simple solutions have emerged. As such, while we are optimistic that greater advertising skepticism may help reduce the impact of the green-feminine association, and remain hopeful that increasing sustainability literacy might reduce negative associations with environmentalism for men in the long-term, we will, until the world changes, support marketing actions that recognize and respond to these implicit associations. Men and women, Mars and Venus-gender differences matter for the care of the Earth.

\section{REFERENCES}

Aiken, L. S., West, S. G., \& Reno, R. R. 1991. Multiple regression: Testing and interpreting interactions. Sage.

Banaji, M., \& Greenwald, A. 2013. Blindspot: Hidden biases of good people. New York: Random House Publishing.

Brough, A., Wilkie, J. E. B., Ma, J., Isaac, M. S., \& Gal, D. 2016. Is eco-friendly unmanly? The green-feminine stereotype and its effect on sustainable consumption. Journal of Consumer Research, 43(4): 567-582.

Davidson, D. J., \& Freudenburg, W. R. 1996. Gender and environmental risk concerns: A review and analysis of available research. Environment and Behavior, 28(3): 302-339.

Dietz, T., Kalof, L., \& Stern, P. 2002. Gender, values, and environmentalism. Social

Science Quarterly, 83(1): 353-364.

Fiske, S. T., \& Taylor, S. E. 2013. Social cognition: From brains to culture. Sage. Friestad, M., \& Wright, P. 1994. The persuasion knowledge model: How people cope with persuasion attempts. Journal of Consumer Research, 21(1): 1-31.

Gladwell, M. 2007. Blink: The power of thinking without thinking. New York: Back Bay Books. 
Gray, J. 1992. Men are from Mars, women are from Venus. New York: HarperCollins.

Greenwald, A. G. 2017. The selling of implicit associations. Presentation to the Seattle University Psychology Department (May 4), Seattle, Washington.

Greenwald, A. G., McGhee, D. E., \& Schwartz, J. L. 1998. Measuring individual differences in implicit cognition: The implicit association test. Journal of Personality and Social Psychology, 74(6): 1464-1480.

Kahneman, D. 2011. Thinking, fast and slow. New York: Farrar, Straus and Giroux.

Lee, J. A., \& Holden, S. J. 1999. Understanding the determinants of environmentally conscious behavior. Psychology and Marketing, 16(5): 373-392.

Obermiller, C., \& Atwood, A. 2014. Measuring sustainability literacy: Scale development. Journal of Jesuit Business Education, 5(1): 105-128.

Obermiller, C., \& Spangenberg, E. 1998. Development of a scale to measure consumer skepticism toward advertising. Journal of Consumer Psychology, 7(2): 159-186.

Spiller, S. A., Fitzsimons, G. J., Lynch Jr., J. G., \& McClelland, G. H. 2013. Spotlights, floodlights, and the magic number zero: Simple effects tests in moderated regression. Journal of Marketing Research, 50(2): 277-288.

Zelezny, L. C., Chua, P.-P., \& Aldrich, C. 2000. Elaborating on gender differences in environmentalism. Journal of Social Issues, 56(3): 443-457.

\section{APPENDIX: SKEP AND SUSTLIT (SHORT FORM) ITEMS (5-POINT LIKERT SCALES)}

\section{SustLit (short form)}

(1 = strongly disagree, 5 = strongly agree $),(R)=$ reverse-scored

1. Human behavior plays a significant part in climate change.

2. Recent mild winters prove that climate change is not happening. (R)

3. Increasing the use of wind turbines could eliminate our dependence on foreign oil within a few years. (R)

4. The largest use of energy per year in a typical U.S. home is lighting. ( $\mathrm{R})$

5. Most electricity in the U.S. is produced by burning coal.

6. The major cause of coral bleaching - the death of coral reefs-is chemical spillage in the oceans. (R) 
7. There is no need to conserve water because water is constantly being replenished by the earth's natural water cycles. (R)

8. Switching from meat to vegetable meals in the U. S. can make cleaner fresh water available to people in developing countries.

9. The earth, plants, and animals exist only for the support of humans. (R)

10. We will always have enough resources. When something runs out, we find it somewhere else or find something else that works just as well. (R)

11. The best way to deal with waste is to seal it away so that it cannot affect us. (R)

12. Abuses of the environment disproportionately diminish the lives of the poor.

13. Businesses should pay their employees and their suppliers fair compensation, even if that is more than the market requires.

14. Businesses have an obligation to make positive contributions to society.

15. On foods, the label "organic" means the food is not genetically modified.

16. On coffee or other products, the label "Fair Trade" means the products are extra high quality. (R)

17. On products, the label "recyclable" means that the material in the product will be used to make more of the same product. (R)

18. A "carbon tax" would prevent the manufacture or sale of products that add carbon to the atmosphere. (R)

19. A "cap and trade" policy for carbon would set a limit on the total amount of carbon added to the atmosphere. 


\section{SKEP}

(1 = strongly disagree, 5 = strongly agree $),(R)=$ reverse-scored

1. We can depend on getting the truth in most advertising. (R)

2. Advertising's aim is NOT to inform the consumer.

3. I believe advertising is informative. (R)

4. Advertising is generally NOT truthful.

5. Advertising is a reliable source of information about the quality and performance of products. (R)

6. Advertising is truth well told. (R)

7. In general, advertising does NOT present a true picture of the product being advertised.

8. I feel I have been accurately informed after viewing most advertisements. (R)

9. Most advertising does NOT provide consumers with essential information. (R)

Carl Obermiller is Professor of Marketing at Albers School of Business, Seattle University. He obtained his Ph.D. at Ohio State University. His current research interests include consumer skepticism and sustainability literacy.

Mathew S. Isaac is Associate Professor at Albers School of Business, Seattle University. He obtained his Ph.D. at Kellogg School of Management, Northwestern University. His research interests include numerical cognition and persuasion knowledge. 